Check for updates

Cite this: Mater. Adv., 2021, 2, 2045

Received 25th September 2020, Accepted 8th February 2021

DOI: 10.1039/d0ma00738b

rsc.li/materials-advances

\section{High performance as-cast P3HT:PCBM devices: understanding the role of molecular weight in high regioregularity $\mathrm{P} 3 \mathrm{HT} \dagger$}

\author{
Naresh Chandrasekaran, (D) ab Anil Kumar, (D) ${ }^{c}$ Lars Thomsen, (D) ${ }^{d}$ Dinesh Kabra (D) *e \\ and Christopher R. McNeill (D) *a
}

\begin{abstract}
The performance of bulk heterojunction $(\mathrm{BHJ})$ organic solar cells is well-known to be influenced by the properties of the donor polymer employed such as its molecular weight (MW) and regioregularity. In this study, four different molecular weight batches of high regioregularity (100\%) poly(3-hexylthiophene) (DF-P3HT) are investigated. Unlike other studies, here the RR of the P3HT is fixed (to 100\%) and the MW of the polymer is varied to understand the influence of $\mathrm{MW}$ on P3HT physical properties such as its electrical, optical and thermal properties and microstructure using $\mathrm{X}$-ray synchrotron techniques. Significantly, it is found that annealing has less of an influence the properties of pristine films of P3HT when the RR of the P3HT is very high. A similar approach is used to examine the physical properties and microstructure of P3HT:PCBM blend films. The properties of the blend films for different $\mathrm{MW}$ are correlated with the performance of the $\mathrm{BHJ}$ solar cells fabricated using $\mathrm{P} 3 \mathrm{HT}$ :PCBM blends. A record high average efficiency of $3.8 \%$ for as-cast devices (no annealing or solvent additive) with best devices reaching performance over $4 \%$ is obtained for DF-P3HT:PCBM with MW of $44 \mathrm{kDa}$. Though there is a marginal variation in the performance of the devices with change in $M W$, no systematic variation in device performance as a function of MW is observed in contrast to other MW studies employed P3HT of lower RR. These findings are attractive in the light of the mass production of polymer solar cells such as via roll-to-roll printing where thermal annealing is not possible or desired.
\end{abstract}

\section{A. Introduction}

Organic photovoltaic (OPV) technology has potential advantage over the inorganic photovoltaics because of its solution processability and low fabrication cost. Because of the low dielectric constant of the organic semiconductors, the binding energy of the primary exciton is in the order of few hundred meV. BHJ organic solar cells are designed by intermixing an electron donating polymer referred as donor (D) and an electron accepting polymer commonly referred as acceptor (A) to overcome the strong coulombic force of primary excitons. ${ }^{1}$ Use of $\mathrm{BHJ}$ has

\footnotetext{
${ }^{a}$ Department of Materials Science and Engineering, Monash University, Wellington Road, Clayton, VIC 3800, Australia. E-mail: christopher.moneill@monash.edu

${ }^{b}$ ARC Centre of Excellence in Exciton Science, Monash University, Clayton, Victoria 3800, Australia

${ }^{c}$ Department of Chemistry, Indian Institute of Technology Bombay, Powai, Mumbai-400076, India

${ }^{d}$ Australian Synchrotron, ANSTO, 800 Blackburn Road, Clayton, Victoria 3168, Australia

${ }^{e}$ Department of Physics, Indian Institute of Technology Bombay, Powai, Mumbai-400076, India. E-mail: dkabra@iitb.ac.in

$\dagger$ Electronic supplementary information (ESI) available. See DOI: 10.1039/ d0ma00738b
}

helped to increase the performance of single junction organic solar cells reaching more than $14 \%$, recently. ${ }^{2,3}$ Among hundreds of materials system available for organic photovoltaic (OPV) technology, P3HT:PCBM is the most extensively examined system. ${ }^{4-6}$ This is due to the simple synthetic route and chemical structure of P3HT which interests the chemist for large scale synthesis. $^{7}$ Since P3HT is the one of the available polymer currently, which can be synthesised over few $\mathrm{kgs}$, makes it a viable candidate for OPV commercialization through large scale manufacturing. ${ }^{5,8}$ Besides this, performance over $6 \%$ has been achieved for P3HT with non-fullerene acceptor which motivates to understand further on this simple homopolymer. ${ }^{9}$

The performance of the $\mathrm{BHJ}$ solar cells is known to be strongly influenced by the properties of the donor polymer including molecular weight (MW), and polymer regioregularity (RR). ${ }^{10-14}$ The enhancement in the device performance with increasing RR has been attributed to improvement in crystallinity and improved $\pi-\pi$ stacking which enhances the charge transport inside the blend as argued by Kim et al. ${ }^{12}$ A detailed study on the positive and negative effects of change in the RR of P3HT on polymer/ $\mathrm{MoO}_{3}$ interface carrier dynamics is explained by us recently. ${ }^{14}$ Mauer et al. and Ebadian et al. also studied the charge transport 
properties and photovoltaic performance of $\mathrm{P} 3 \mathrm{HT}$ polymers for different regioregularities. ${ }^{15,16}$ They found the batches of P3HT with RR 94\% and 98\% showed similar solar cell performance despite variation in RR. The reason for this discrepancy was explained in terms of the difference in other parameters such as MW. Interestingly in the study of Kim et al., the higher RR batch also possessed a higher MW than the batches of lower RR used, suggesting a potential influence of $\mathrm{MW}$ in addition to $\mathrm{RR}$ in their study. In the study of Mauer et al. the MW was similarly different for the different RR batches studied. In this case, the higher RR polymers had lower weight averaged $\mathrm{MW}\left(M_{\mathrm{w}} \approx 25 \mathrm{kDa}\right)$ while the lower RR polymer had higher weight averaged $\mathrm{MW}\left(M_{\mathrm{w}} \approx 60 \mathrm{kDa}\right)$ which lead to similar device performance. Ebadian et al. had opposite trend of weight averaged MW and RR to Mauer et al. study, but the dispersity $(\nexists)$ of these polymers are not defined and hence a solid correlation cannot be derived. ${ }^{16}$ This observation also suggests that in order to understand the effect of MW, a more systematic investigation by keeping other polymer parameters like regioregularity constant is necessary.

Several studies have previously correlated the MW of P3HT with device performance and material properties. ${ }^{17,18}$ Liu et al., for example, investigated how photovoltaic performance, crystallinity and the optical absorption spectra vary with changes in the MW of $\mathrm{P} 3 \mathrm{HT} .{ }^{19}$ The maximum performance was achieved for P3HT with intermediate number averaged molecular weight $\left(M_{\mathrm{n}} \approx 20 \mathrm{kDa}\right)$ in this study. The variation of morphology and device performance with change in P3HT MW was also studied by Spoltore et al. ${ }^{20}$ They observed a decrease in solar cell performance with increase in the MW of P3HT. Morana et al. observed improved solar cell performance for cells with higher MW. ${ }^{21}$ This ambivalence in the trend is likely due to variations of polymer RR in addition to the MW and device processing conditions like thermal treatment. ${ }^{22}$ Polymer RR and MW are closely related with each-other as discussed in the previous paragraph.

In this paper, we try to resolve the existing ambiguity using P3HTs with high regioregularity. Four different P3HT with varying $\mathrm{MW}\left(M_{\mathrm{w}} \approx 37-88 \mathrm{kDa}\right)$ and constant $\mathrm{RR}(100 \%)$ are studied which have been prepared using continuous flow synthesis. ${ }^{13}$ These batches of P3HT with high RR are referred as DF-P3HT throughout this paper. ${ }^{13,23,24}$ To enable comparison with previous studies that investigated lower RR P3HT, a batch of $\mathrm{P} 3 \mathrm{HT}$ with $92 \% \mathrm{RR}\left(M_{\mathrm{w}} \approx 52 \mathrm{kDa}\right)$ is also included in this study.

As mentioned earlier, device processing conditions such as solvent additives, solvent treatment and thermal annealing also play important roles in determining the physical properties, microstructure and performance of BHJ solar cells. ${ }^{25-27}$ Thermal annealing is found to improve the crystallinity, domain purity and phase segregation in P3HT:PCBM blends. ${ }^{28,29}$ To make a comprehensive study, along with differences in MW, the thermal annealing condition for device fabrication is also varied to ensure that the optimum thermal process is employed for each batch. This paper therefore provides a thorough investigation of how changes in MW for high RR P3HT and how different annealing conditions affect the physical properties, microstructure and photovoltaic performance of P3HT-based films. The crystallinity and HOMO levels of the polymers are examined using differential scanning calorimetry (DSC) and photoelectron spectrometer in air (PESA), respectively. The exciton bandwidth $(W)$ of the aggregates is extracted from UV-Vis absorption spectra of pristine and P3HT:PCBM blend films. The microstructure of the pristine P3HT and P3HT:PCBM films are studies using a combination of synchrotron-based grazing incidence wide-angle X-ray scattering (GIWAXS) and near-edge X-ray absorption fine structure (NEXAFS) spectroscopy. The change in the optical and microstructure properties of the P3HT:PCBM blends are also correlated with the performance of the $\mathrm{BHJ}$ solar cells.

\section{B. Results and discussion}

\section{Pristine P3HT films}

The donor polymer properties like MW, regioregularity and poly-dispersity index $(\nexists)$ are tabulated in Table 1 .

Electronic properties. The packing of polymer chains in solid state and the orientation of the backbone thiophene rings determine the electronic states (HOMO and LUMO) of the polymer. ${ }^{30}$ The ionisation potential or highest occupied energy levels of pristine P3HT thin films on ITO substrates was measured using PESA. ${ }^{31}$ The recorded HOMO levels obtained for different P3HT samples are summarised in Table 1. Deeper HOMO levels are observed for the batches of DF-P3HT with lower MW. Specifically, the HOMO energy goes from $4.58 \mathrm{eV}$ for $88 \mathrm{kDa}$ DF-P3HT to $4.62 \mathrm{eV}$ for $37 \mathrm{kDa}$. Although a systematic trend is observed between HOMO levels and DF-P3HT MW, the change is within the error value of the instrument and hence may not be significant. The HOMO level of the reduced RR batch (rr-P3HT) is also found to have a deeper HOMO level (4.66 eV) compared to the other DF polymers. This is consistent with our previous observations, where it was found that an increase in polymer RR moves the HOMO energy level toward the vacuum level and hence the $E_{\mathrm{CT}}$ energy inside the blend decreases. $^{23}$

Thermal properties. The thermal properties of $\mathrm{P} 3 \mathrm{HT}$ polymers are studied using the second heating curve from DSC measurement (see Fig. S1, ESI $\dagger$ ). The melting temperatures determined from Fig. S1 (ESI $\dagger$ ) are summarised in Table 1. With increase in MW of DF-P3HT from $37 \mathrm{kDa}$ up until $70 \mathrm{kDa}$, an increase in the melting point is observed going from $232.9{ }^{\circ} \mathrm{C}$ for the $37 \mathrm{kDa}$ batch to $238.0{ }^{\circ} \mathrm{C}$ for the $70 \mathrm{kDa}$, suggesting an increase in the crystal size. ${ }^{24}$ Interestingly, there is a decrease in the melting point with further increase in molecular weight to $88 \mathrm{kDa}$, suggesting the onset of chain

Table 1 Physical properties of different P3HT polymers used in this study

\begin{tabular}{lllllll}
\hline P3HT & $M_{\mathrm{w}}(\mathrm{kDa})$ & $\mathrm{RR}(\%)$ & $D$ & HOMO $(\mathrm{eV})$ & $\Delta H\left(\mathrm{~J} \mathrm{~g}^{-1}\right)$ & Mel. temp. $\left({ }^{\circ} \mathrm{C}\right)$ \\
\hline DF & 37 & 100 & 1.4 & $4.62 \pm 0.02$ & 15.42 & 232.9 \\
DF & 44 & 100 & 1.5 & $4.60 \pm 0.01$ & 15.38 & 236.8 \\
DF & 70 & 100 & 1.3 & $4.61 \pm 0.02$ & 15.83 & 238.0 \\
DF & 88 & 100 & 1.6 & $4.58 \pm 0.02$ & 16.20 & 233.6 \\
rr & 52 & 92 & 2.4 & $4.66 \pm 0.03$ & 12.77 & 222.1
\end{tabular}


folding at this MW. For the lower RR batch, a much lower melting point of $222{ }^{\circ} \mathrm{C}$ is observed. Comparing the $44 \mathrm{kDa}$ DF-P3HT and $52 \mathrm{kDa}$ rr-P3HT batches, the melting point has increased by more than $14{ }^{\circ} \mathrm{C}$ with increase in regioregularity from $92 \%$ to $100 \%$ suggesting an increase in crystal size with increase in RR. This is similar to that observed by Khon et al., where a single tail-to-tail defect was found to change the melting point of the polymer. ${ }^{24}$ The enthalpy of fusion $(\Delta H)$ was calculated by integrating the area under the endothermal peak with the results shown in the Table 1. Similar values of $\Delta H$ are observed for the low MW DF-P3HT batches $37 \mathrm{kDa}$ and $44 \mathrm{kDa})$ with a slight increase in $\Delta H\left(c a .0 .8 \mathrm{~J} \mathrm{~g}^{-1}\right)$ when the MW is increased to $88 \mathrm{kDa}$. This observation suggests that the degree of crystallinity of the DF P3HT samples is similar when the RR of the P3HT is very high. In contrast, for the $92 \%$ RR batch, a significantly lower $\Delta H$ value of $12.8 \mathrm{~J} \mathrm{~g}^{-1}$ is measured, suggesting a reduced degree of crystallinity for the rr-P3HT batch.

Optical properties. The Fig. S2 (ESI $\dagger$ ) shows the UV-Vis absorption spectra of pristine-P3HT films with different annealing conditions. The absorption shoulder at $2.05 \mathrm{eV}$ is attributed to the $0-0$ band transition and the peak at $2.25 \mathrm{eV}$ is attributed to the $0-1$ optical transition. ${ }^{32,33}$ The ratio of the $0-0$ and $0-1$ peak is related to the free exciton bandwidth of the aggregates $W$ of the donor polymer and $E_{\mathrm{p}}$ which is the energy of intramolecular vibration as shown in the equation below, ${ }^{32,34}$

$$
\frac{A_{0-0}}{A_{0-1}}=\left(\frac{1-0.24 W / E_{\mathrm{p}}}{1+0.073 W / E_{\mathrm{p}}}\right)^{2}
$$

$A$ value of $0.18 \mathrm{eV}$ is assigned to $E_{\mathrm{p}}$ assuming that the intramolecular interaction is dominated by the $\mathrm{C}=\mathrm{C}$ symmetric stretch. ${ }^{35}$ The values of $W$ calculated for the different pristine P3HT samples using the above equation are show in the Fig. S2d (ESI $\dagger$ ). It is evident from Fig. $2 d$ that $W$ increases with increase in MW for the DF-P3HT polymers. This suggests that the conjugation length of the polymer backbone decreases with increase in MW. Fig. S2b and c (ESI $\dagger$ ) show the normalized absorption spectra for pristine films annealed at $100{ }^{\circ} \mathrm{C}$ and $150{ }^{\circ} \mathrm{C}$ for ten minutes, respectively. The free exciton bandwidth decreases slightly after annealing for the low MW DF-P3HT batches (37 kDa and $44 \mathrm{kDa}$ ), but an opposite effect is observed for the high MW DF-P3HT sample, where annealing is found to increase $W$ suggesting a decrease in the conjugation length of high MW polymer with annealing. Fig. S2d (ESI $\dagger$ ) also plots $W$ for the low RR batch (rr-P3HT) which exhibits a higher $W$ value as compared to DF-P3HT films suggesting that the conjugation length of rr-P3HT polymer films is much lower than DF-P3HT films. Thermal annealing on rr-P3HT films increases the conjugation length along the polymer backbone since the $W$ decreases with annealing.

Complementary to absorption measurements, resonant Raman spectroscopy measurements on pristine P3HT thin films were also conducted. The Raman spectra of the different DF-P3HT and rr-P3HT polymer as-cast films are shown in Fig. 1. Raman spectroscopy is used to probe different vibrational
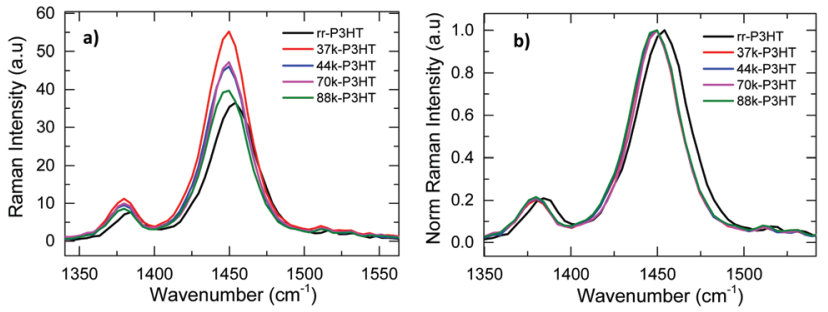

Fig. 1 Resonant Raman spectra of different as-cast P3HT donor polymers with $532 \mathrm{~nm}$ wavelength excitation. (a) The Raman scattering intensity is normalised with the thickness of the film, (b) Raman spectra normalized with $\mathrm{C}=\mathrm{C}$ stretching peak maximum intensity.

modes inside the $\mathrm{P} 3 \mathrm{HT}$ polymer chain, including the $\mathrm{C}-\mathrm{S}-\mathrm{C}$ deformation, $\mathrm{C}-\mathrm{H}$ bending, $\mathrm{C}-\mathrm{C}$ inter and intra-ring stretching, and $\mathrm{C}=\mathrm{C}$ in-plane stretching. ${ }^{36-39}$ Among these modes the $\mathrm{C}=\mathrm{C}$ in-plane ring skeleton mode which corresponds to ca. $1440 \mathrm{~cm}^{-1}$ wavenumber and $\mathrm{C}-\mathrm{C}$ intra ring skeleton mode corresponding to wavenumber $c a .1380 \mathrm{~cm}^{-1}$ are important for charge transport along the $\mathrm{P} 3 \mathrm{HT}$ polymer chain. ${ }^{38,40,41}$ It has been previously shown that ordering of P3HT chains causes a shift of the $\mathrm{C}=\mathrm{C}$ in-plane ring skeleton stretching mode peak towards lower wavenumber, changes the intensity of the peak and also decreases the FWHM of the $\mathrm{C}=\mathrm{C} 1440 \mathrm{~cm}^{-1}$ and C-C $1378 \mathrm{~cm}^{-1}$ modes. ${ }^{37,41}$ From Fig. 1a it is found that the $1440 \mathrm{~cm}^{-1}$ and $1378 \mathrm{~cm}^{-1}$ peak Raman intensity (that has been normalized with respect to the thickness of the film) varies with MW and RR of the as-cast P3HT polymer. A decrease in the intensity of the $\mathrm{C}=\mathrm{C}$ and $\mathrm{C}-\mathrm{C}$ stretching modes peaks are observed with increase in the MW of the DF-P3HT polymer. The low regioregularity $\mathrm{P} 3 \mathrm{HT}$ batch also has a lower $1440 \mathrm{~cm}^{-1}$ and $1378 \mathrm{~cm}^{-1}$ peak intensities as compared to the DF-P3HT films. From Fig. $1 \mathrm{~b}$ it is observed that the $\mathrm{C}=\mathrm{C}$ and $\mathrm{C}-\mathrm{C}$ stretching modes peaks of the low regioregularity film are shifter toward higher wavenumber by $c a .5 \mathrm{~cm}^{-1}$ when compared to the $44 \mathrm{kDa}$ DF-P3HT polymer film, further confirming the increased disorder in the rr-P3HT film compared to the DF-P3HT film. No significant shift in the Raman peak position with change in the MW is seen for the DF-P3HT polymers.

Microstructure. Fig. S2 and S3 (ESI $\dagger$ ) shows the 2D GIWAXS scattering profiles for as-cast pristine and annealed P3HT films, respectively. The peaks observed along the vertical direction (referred as the out-of-plane (OOP) direction) at $q$ values of $q_{z}=0.37,0.75$ and $1.1 \AA^{-1}$ are attributed to (100), (200) and (300) reflections, respectively. ${ }^{28}$ The fact that these alkyl stacking peaks are observed along the out-of-plane direction indicates that the P3HT crystallites in all samples are packing edge-on to the substrate, with no significant difference in crystallite orientation between samples. The one-dimensional out-of-plane (OOP) and in-plane (IP) scattering profiles extracted from the two-dimensional scattering images are shown in the Fig. 2. Examining the 1-D scattering profile along the OOP direction the peak at $q=0.37 \AA^{-1}$ indexed as the (100) peak corresponds to the alkyl stacking direction, with the peak position enabling determination of the alkyl stacking $d$-spacing $\left(d_{\text {alk }}\right)$. From the scattering profile for the pristine as-cast P3HT 
(a)

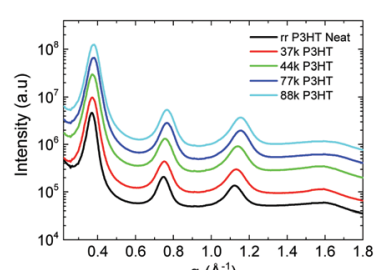

(c)

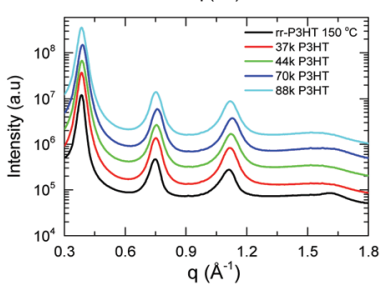

(b)

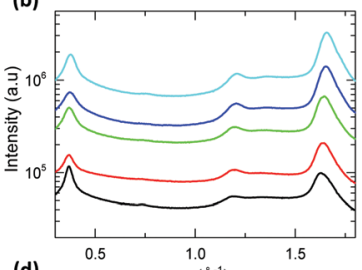

$\mathrm{q}\left(\AA^{-1}\right)$

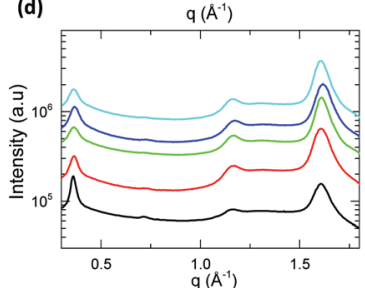

Fig. 2 One-dimensional GIWAXS scattering profile of pristine as-cast P3HT polymer (a) along OOP and (b) along IP direction; $150{ }^{\circ} \mathrm{C}$ thermally annealed films (c) along OOP and (d) along IP direction.

films in OOP direction, one can observe that the alkyl stacking peak shifts to higher $q$ values with increase in the MW. This indicates that with an increase in MW there is a decrease in the alkyl stacking $d$-spacing. The parameters extracted from the onedimensional scattering profiles are summarised in Table 2. The alkyl stacking $d$-spacing of the as-cast pristine films decreases from $1.7 \mathrm{~nm}$ for $37 \mathrm{kDa}$ DF-P3HT to $1.65 \mathrm{~nm}$ for $88 \mathrm{kDa}$ DF-P3HT. This is opposite to what was observed by Liu et al., ${ }^{19}$ where an increase in alkyl stacking $d$-spacing with increasing MW was reported. Once the films are annealed to $150{ }^{\circ} \mathrm{C}$, the MW dependency of $d$-spacing vanishes and a constant value of ca. $1.7 \mathrm{~nm}$ recorded for all batches (see values inside parentheses in Table 2). The peak found at $q_{x y}=1.58 \AA^{-1}$ in the IP scattering profile is identified as the $\pi-\pi$ scattering peak. The $\pi-\pi$ stacking $d$-spacings $\left(d_{\pi-\pi}\right)$ for the different P3HT films are all very similar at around $0.38 \mathrm{~nm}$. The alkyl stacking ( $\left.\xi_{\text {alk }}\right)$ and $\pi-\pi$ stacking $\left(\xi_{\pi-\pi}\right)$ coherence lengths of the different polymers have also be calculated and are summarised in Table 2. The alkyl stacking coherence length is similar for all as-cast DF samples at around $12.5 \mathrm{~nm}$. For annealed DF-P3HT films the coherence length increases to $\sim 17 \mathrm{~nm}$ for most batches with a slightly higher value of $19.2 \mathrm{~nm}$ for the $37 \mathrm{kDa}$ batch. In the case of the rr-P3HT batch, the alkyl stacking coherence length is higher than that found for the DF batches with a value of $15.7 \mathrm{~nm}$ for the as-cast film and $20.5 \mathrm{~nm}$ for the annealed film. Examining the $\pi-\pi$ stacking coherence lengths, it is evident that the $\pi-\pi$ stacking coherence length of the as-cast films increases with increasing

Table 2 Parameters extracted from fitting 1-D GIWAXS scattering profile of pristine P3HT films. The values mentioned inside the parentheses correspond to $150{ }^{\circ} \mathrm{C}$ thermally annealed films

P3HT $\quad d_{\text {alk }}(\mathrm{nm}) \quad \xi_{\text {alk }}(\mathrm{nm}) \quad \xi_{\pi-\pi}(\mathrm{nm})$

37 kDa DF-P3HT $1.70 \pm 0.01(1.70) \quad 12.8 \pm 0.1(19.2) \quad 7.1 \pm 0.2(7.8)$ $\begin{array}{lllll}44 \mathrm{kDa} \text { DF-P3HT } & 1.68 \pm 0.01(1.70) & 12.3 \pm 0.2(17.1) & 7.6 \pm 0.1(9.4)\end{array}$ $70 \mathrm{kDa}$ DF-P3HT $1.66 \pm 0.01(1.68) \quad 12.4 \pm 0.1(17.2) \quad 8.0 \pm 0.1(8.2)$ $88 \mathrm{kDa}$ DF-P3HT $1.66 \pm 0.02(1.70) \quad 12.5 \pm 0.2(17.3) \quad 8.2 \pm 0.1(8.7)$ rr-P3HT $1.69 \pm 0.02(1.7) \quad 15.7 \pm 0.2(20.5) \quad 6.7 \pm 0.1(8.3)$

MW. The as-cast $37 \mathrm{kDa}$ DF-P3HT batch shows a $\pi-\pi$ stacking coherence length of $7 \mathrm{~nm}$ which increases to $c a .8 .2 \mathrm{~nm}$ for the $88 \mathrm{kDa}$ DF-P3HT batch. This increase in the coherence length of the polymer with increase in the MW is consistent with the improvement in the crystallinity of the material with increasing MW as observed from the DSC measurements. Annealing of the P3HT films at $150{ }^{\circ} \mathrm{C}$ disturbs the dependence of coherence length on MW; with the $44 \mathrm{kDa}$ DF-P3HT batch exhibiting the highest $\pi-\pi$ stacking coherence length of $9.4 \mathrm{~nm}$. In rr-P3HT, the as-cast films show $\pi-\pi$ coherence length of $6.7 \mathrm{~nm}$ which upon annealing increases to $8.3 \mathrm{~nm}$. The as-cast rr-P3HT films have the lowest $\pi-\pi$ coherence length as compared to other P3HT batches, suggesting high degree of disorder.

\section{P3HT:PCBM blends}

Optical properties. The Fig. S4 (ESI $\dagger$ ) shows the linear UV-Vis absorption spectra of different MW DF-P3HT:PCBM blends. Fig. S4a (ESI $\dagger$ ) shows the spectra of as-cast films, while Fig. S4b (ESI $\dagger$ ) shows the spectra of films annealed at $100{ }^{\circ} \mathrm{C}$ and Fig. S4c (ESI $\dagger$ ) shows the spectra of films annealed at $150{ }^{\circ} \mathrm{C}$. Qualitatively, the as-cast DF-P3HT:PCBM blends exhibit pronounced vibronic features suggesting that ordered aggregates are produced in as-cast blends with PCBM. The rr-P3HT:PCBM blend exhibits much stronger absorption at higher photon energies consistent with a higher proportion of disordered chains in this blend compared to those based on DF-P3HT batches. Annealing removes some of the disparity between the rr-P3HT:PCBM blend and the DF-P3HT:PCBM blends but not entirely. The free exciton bandwidths $W$ extracted from the spectra are potted in Fig. S4d (ESI $\dagger)$. While for pristine P3HT films $W$ was observed to systematically increase with increasing MW, this is not the case for DF-P3HT:PCBM films. For the $37 \mathrm{kDa}$ DF-P3HT batch, the addition of PCBM has caused the $W$ to increase from $c a .82 \mathrm{meV}$ (pristine) to $92 \mathrm{meV}$ (blend). For the other DF batches the absolute value of $W$ decreases with the addition of PCBM. For the higher MW batches of DF-P3HT, $W$ of the blends increases with annealing suggesting decrease in the coherence length of the polymer chain. For the rr-P3HT: PCBM sample annealing decreases the value of $W$ suggesting an increase in the conjugation length of the P3HT:PCBM with annealing. From the $W$ values of the blend films, one can expect that the performance of the DF-P3HT:PCBM blends should decrease with annealing at $150{ }^{\circ} \mathrm{C}$ while for the rr-P3HT:PCBM sample annealing should increase the performance of the solar cell. The device performance of these samples is discussed later in this paper.

The normalized Raman spectra of P3HT:PCBM blend films excited with $532 \mathrm{~nm}$ are shown in the Fig. S6 (ESI $\dagger$ ). No significant shift in the wavenumber of the $\mathrm{C}=\mathrm{C}$ stretching mode is seen. However the relative intensity of the $\mathrm{C}-\mathrm{C}$ intraring stretching bond at $\sim 1378 \mathrm{~cm}^{-1}$ is found to change with changing MW of the P3HT (see Fig. S6b, ESI $\dagger$ ). In particular a higher C-C Raman peak intensity is found for $44 \mathrm{kDa}$ and $70 \mathrm{kDa}$ DF-P3HT, attributing to more ordered P3HT phases in these blends. ${ }^{41}$ This is agreement with the $W$ 
parameter calculated from the absorption measurements of the P3HT:PCBM blends.

Microstructure. Fig. S7 and S8 (ESI $\dagger$ ) show the two-dimensional GIWAXS scattering images of as-cast and thermally annealed P3HT:PCBM films, respectively. The one-dimensional scattering profiles of these films are shown in Fig. 3. Similar alkyl stacking and $\pi-\pi$ stacking features are observed, with additional scattering from PCBM aggregates in the form of a broad isotropic ring at $\sim 1.4 \AA^{-1}$. Again, a preferential stacking of P3HT crystallites edge-on to the substrate is observed. The alkyl stacking $d$-spacing for these blends is found to have a maximum value of $1.65 \mathrm{~nm}$ for intermediate MW (44 kDa) DF-P3HT:PCBM films, with the alkyl stacking $d$-spacing for the highest MW DF-P3HT:PCBM slightly lower at is decreased to $1.63 \mathrm{~nm}$ (see Table 3). In general the alkyl stacking $d$-spacings for the as-cast blends are lower than those observed in the as-cast pristine films. The $\pi-\pi$ stacking $d$-spacing value remains constant at $0.38 \mathrm{~nm}$ for all different MW of DF-P3HT:PCBM blends. Once the blend films are annealed the alkyl stacking $d$-spacings are all $\sim 1.70 \mathrm{~nm}$ for all samples. The coherence length of the polymer chain along the alkyl direction in the as-cast DF-P3HT:PCBM films reaches a maximum and for the $37 \mathrm{kDa}$ MW DF-P3HT: PCBM blend. Annealing these films lead to an increased alkyl stacking coherence of at least by $2 \mathrm{~nm}$ for all different MW DFP3HTs, with a more significant increase for the higher MW batches. The coherence lengths of the polymer chain along the $\pi-\pi$ direction are also summarised in Table 3 . The $\pi-\pi$ stacking coherence lengths show similar values for as-cast films ( $\sim 9$ to $10 \mathrm{~nm}$ ). Interestingly these values are higher than those observed for as-cast pristine samples. When comparing the rr-P3HT:PCBM and 44 kDa DF-P3HT:PCBM blends, the $\xi_{\pi-\pi}$ is observed to increase from $8.4 \mathrm{~nm}$ to $9.8 \mathrm{~nm}$ with improvement in RR. This is consistent with what was observed from Raman and UV-Vis absorption measurements. Once the blend films are thermally annealed the coherence length along $\pi-\pi$ direction for all different MW DF-P3HT blend films reduces when compared to as-cast films. On the other hand, the coherence length
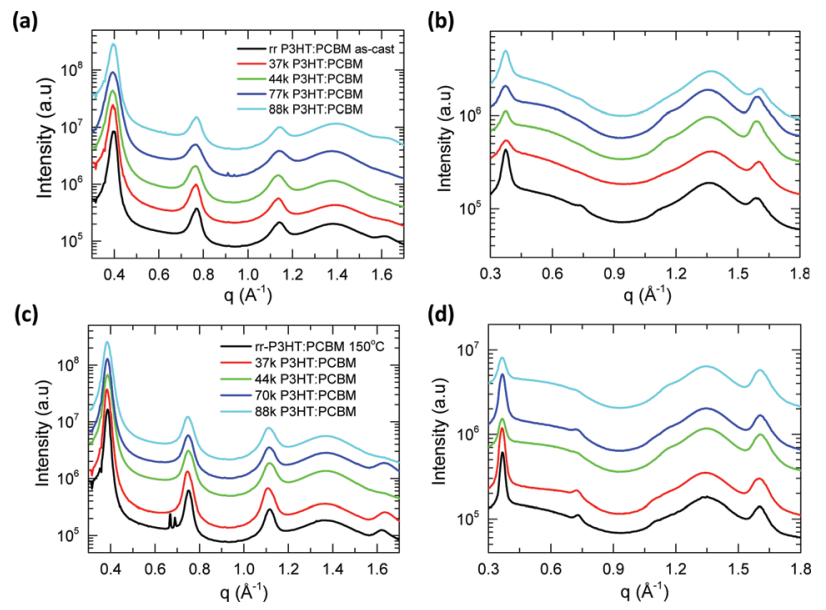

Fig. 3 One-dimensional GIWAXS scattering profile of as-cast P3HT:PCBM blends (a) along OOP and (b) along IP direction; $150{ }^{\circ} \mathrm{C}$ thermally annealed blend films (c) along OOP and (d) along IP direction.
Table 3 Parameters extracted from fitting of the 1-D GIWAXS scattering profile of P3HT:PCBM blend films. The values mentioned inside the braces correspond to $150{ }^{\circ} \mathrm{C}$ thermally annealed blend films

P3HT $\quad d_{\text {alk }}(\mathrm{nm}) \quad \xi_{\text {alk }}(\mathrm{nm}) \quad \xi_{\pi-\pi}(\mathrm{nm})$

37 kDa DF-P3HT $1.64 \pm 0.01(1.70) \quad 19.8 \pm 0.3(21.7) \quad 8.8 \pm 0.2(7.0)$ $\begin{array}{lllll}44 \mathrm{kDa} \text { DF-P3HT } & 1.65 \pm 0.01(1.70) & 14.2 \pm 0.2(19.4) & 9.8 \pm 0.1(7.8)\end{array}$ $70 \mathrm{kDa}$ DF-P3HT $1.64 \pm 0.01(1.68) \quad 12.6 \pm 0.2(21.2) \quad 10 \pm 0.2(8.5)$ $88 \mathrm{kDa}$ DF-P3HT $1.63 \pm 0.02(1.70) \quad 16.5 \pm 0.2(18.9) \quad 8.6 \pm 0.1(7.6)$ $\begin{array}{llll}\text { rr-P3HT } & 1.63 \pm 0.01(1.70) & 20.1 \pm 0.2(29.1) & 8.4 \pm 0.1(9.7)\end{array}$

of rr-P3HT:PCBM films increases from $8.4 \mathrm{~nm}$ to around $9.7 \mathrm{~nm}$ after thermal annealing. This shows the effect of thermal annealing on microstructure is sensitive to the polymer regioregularity where for high RR P3HT:PCBM blends annealing reduces the $\pi-\pi$ coherence length and for lower RR P3HT blends an opposite effect is observed.

Near-edge X-ray absorption fine structure (NEXAFS) spectroscopy was used to study the chemical composition of the top surface of the P3HT:PCBM blend films. Fig. 4(a) shows the total electron yield (TEY) carbon K-edge NEXAFS spectra, of different RR and MW as-cast (solid line) and annealed (dotted) P3HT:PCBM blends measured at an angle of incidence of $55^{\circ}$. The two peaks at $284.5 \mathrm{eV}$ and $285.3 \mathrm{eV}$ corresponds to $\mathrm{C} 1 \mathrm{~s} \rightarrow$ $\pi^{*}$ resonant transitions of PCBM and $\mathrm{P} 3 \mathrm{HT}$, respectively. ${ }^{28,42}$

The NEXAFS spectra of blend films were fitted with pristine P3HT and PCBM NEXAFS spectra to determined chemical composition of the surface of the blend, with the results shown in Fig. S9 (ESI $\dagger$ ). Because of the vertical phase separation and to reduce the surface energy in the P3HT:PCBM blends, the top (air interface) and bottom (PEIE interface) surface of the blends have a 1-2 nm thick P3HT and PCBM layers, respectively. ${ }^{43}$ From the figure below, both as-cast and annealed films has top P3HT rich surface which is consistence with the previous observations. $^{28,43}$ The top surface of the as-cast P3HT:PCBM films, the composition of the P3HT on the surface systematically decreases with increasing MW and RR of the P3HT polymer. Even though there is a trend observed between the P3HT surface composition and MW, the change in the percentage of composition is not significant. It is also to be noted that the rr-P3HT blend has higher P3HT surface composition of $84.5 \%$ (after annealing $82.1 \%$ ), which can facilitate hole
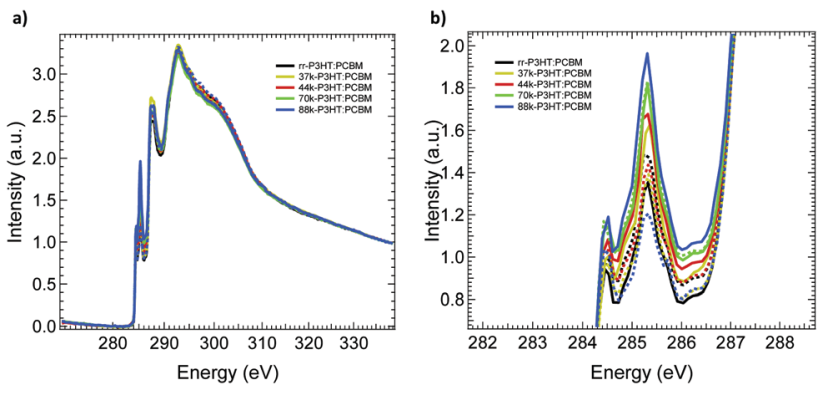

Fig. 4 (a) Carbon K-edge NEXAFS spectra of P3HT:PCBM blend, (b) NEXAFS spectra highlighting $C 1 s \rightarrow \pi^{*}$ of P3HT and PCBM peaks. Solid lines correspond to as-cast films and dotted lines correspond to thermally annealed blend films. 
extraction in the inverted device configuration. ${ }^{43}$ After annealing, the surface composition of P3HT decreases for all batches of P3HT as shown in the figure except for the $44 \mathrm{kDa}$ DF-P3HT.

\section{Solar cell performance}

Fig. S10 (ESI $\dagger$ ) shows the $J-V$ characteristics of the best performing - P3HT:PCBM devices. Average parameters (based on 16 cells) extracted from the $J-V$ curves are shown in Fig. 5 . Fig. 5a shows the short circuit current density as a function of MW and annealing temperature. The $37 \mathrm{kDa}$ DF-P3HT as-cast device shows the lowest current density of $7.6 \mathrm{~mA} \mathrm{~cm}{ }^{-2}$ when compared to other DF-P3HT:PCBM devices in this study. For the $44 \mathrm{kDa}$ and $70 \mathrm{kDa}$ batches, the highest $J_{\mathrm{SC}}$ values are recorded for mild annealing $\left(100{ }^{\circ} \mathrm{C}\right.$ for $\left.10 \mathrm{~min}\right)$ with the $44 \mathrm{kDa}$ cells exhibiting an average $J_{\mathrm{SC}}$ value of $10.3 \mathrm{~mA} \mathrm{~cm}{ }^{-2}$. Annealing these cells to $150{ }^{\circ} \mathrm{C}$ actually results in a decrease in $J_{\mathrm{SC}}$. For the low MW (37 kDa) high MW (88 kDa) DF-P3HT:PCBM cells, annealing to $150{ }^{\circ} \mathrm{C}$ results in the highest $J_{\mathrm{SC}}$, with the $88 \mathrm{kDa}$ DF-P3HT:PCBM cell exhibiting a $J_{\text {SC }}$ of $10.3 \mathrm{~mA} \mathrm{~cm}$ cm $^{-2}$. Fig. 5b shows fill-factor (FF) of the devices with respect to different MW of DF-P3HT. The $37 \mathrm{kDa}$ DF-P3HT:PCBM cells exhibit the lowest FF with values of only $c a$. $56 \%$. The FF reaches maximum for as-cast $44 \mathrm{kDa}$ P3HT:PCBM devices with values over $65 \%$. Such a high fill factor is remarkable for P3HT cells produced without any thermal annealing and without the use of any solvent additives. Comparing the $\mathrm{FF}$ of as-cast $45 \mathrm{kDa}, 70 \mathrm{kDa}$ and $88 \mathrm{kDa}$ devices, the fill factor decreases with increasing MW. After thermal annealing at $150{ }^{\circ} \mathrm{C}$ on all these three different MW devices, the FF values are reduced when compared to as-cast devices. This could be because of the decrease in the conjugation length of the polymers as observed from UV-Vis and Raman measurements. Comparison (see Table 4) between P3HTs with different RR and similar MW suggests decrease in the FF values with decrease in RR values. This change in FF values among P3HTs with different RR can be ascribed to decrease in the mobilities values with decrease in
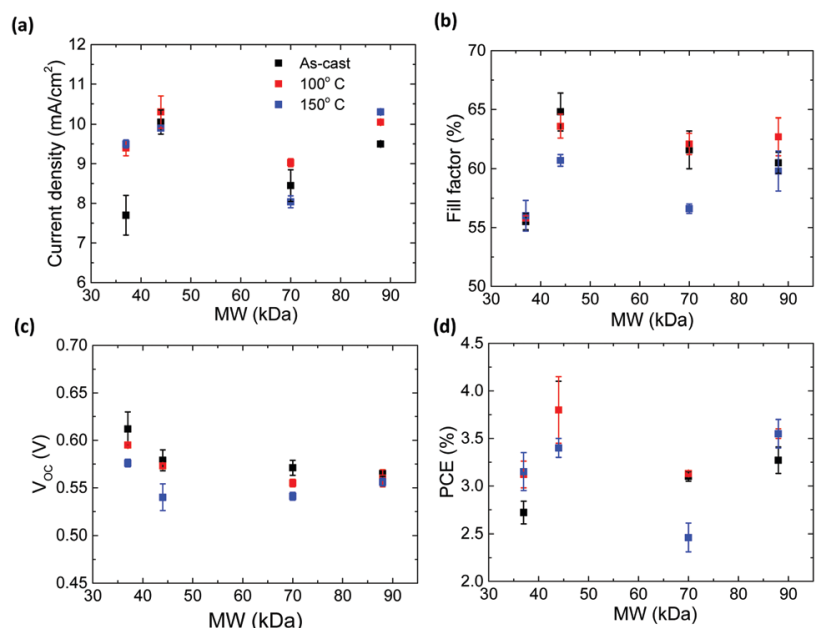

Fig. 5 Mean device parameters from 16 solar cells fabricated using different P3HT:PCBM blends; (a) current density vs. MW (b) fill-factor vs. MW (c) VOc vs. MW and (d) PCE vs. MW.
Table 4 Solar cell device parameters with mean performance values calculated from 16 devices of different MW P3HT:PCBM devices at different annealing conditions

\begin{tabular}{|c|c|c|c|c|c|}
\hline P3HT & $\begin{array}{l}\text { Annealing } \\
\text { condition }\end{array}$ & $J_{\mathrm{SC}}\left(\mathrm{mA} \mathrm{cm}^{-2}\right)$ & $\mathrm{FF}(\%)$ & $V_{\mathrm{OC}}(\mathrm{V})$ & PCE (\%) \\
\hline \multirow[t]{3}{*}{$37 \mathrm{kDa}$} & As-cast & 7.7 & 55.5 & 0.61 & $2.70 \pm 0.12$ \\
\hline & $100{ }^{\circ} \mathrm{C}$ & 9.4 & 55.8 & 0.59 & $3.1 \pm 0.14$ \\
\hline & $150{ }^{\circ} \mathrm{C}$ & 9.5 & 56.0 & 0.58 & $3.2 \pm 0.20$ \\
\hline \multirow[t]{3}{*}{$44 \mathrm{kDa}$} & As-cast & 10.1 & 64.8 & 0.58 & $3.8 \pm 0.30$ \\
\hline & $100{ }^{\circ} \mathrm{C}$ & 10.3 & 63.6 & 0.57 & $3.8 \pm 0.35$ \\
\hline & $150{ }^{\circ} \mathrm{C}$ & 9.9 & 60.7 & 0.54 & $3.4 \pm 0.10$ \\
\hline \multirow[t]{3}{*}{$70 \mathrm{kDa}$} & As-cast & 8.45 & 61.6 & 0.57 & $3.1 \pm 0.05$ \\
\hline & $100{ }^{\circ} \mathrm{C}$ & 9.0 & 62.1 & 0.56 & $3.1 \pm 0.03$ \\
\hline & $150{ }^{\circ} \mathrm{C}$ & 8.1 & 56.6 & 0.54 & $2.5 \pm 0.15$ \\
\hline \multirow[t]{3}{*}{$88 \mathrm{kDa}$} & As-cast & 9.5 & 60.5 & 0.56 & $3.3 \pm 0.14$ \\
\hline & $100{ }^{\circ} \mathrm{C}$ & 10.1 & 62.7 & 0.55 & $3.6 \pm 0.05$ \\
\hline & $150{ }^{\circ} \mathrm{C}$ & 10.3 & 59.8 & 0.56 & $3.6 \pm 0.15$ \\
\hline \multirow[t]{3}{*}{ rr-P3HT } & As-cast & 7.3 & 50.2 & 0.61 & $2.2 \pm 0.15$ \\
\hline & $100{ }^{\circ} \mathrm{C}$ & 8.4 & 50.2 & 0.60 & $2.6 \pm 0.10$ \\
\hline & $150{ }^{\circ} \mathrm{C}$ & 9.0 & 60.1 & 0.59 & $3.2 \pm 0.10$ \\
\hline
\end{tabular}

the RR as reported earilier. ${ }^{14,23}$ The $V_{\mathrm{OC}}$ of the DF-P3HT:PCBM solar cells decreases with increase in the MW as shown in the Fig. 5 c. It can be also observed from the figure that as-cast devices have high $V_{\mathrm{OC}}$, with thermal annealing of the films reducing the $V_{\mathrm{OC}}$ of the devices. The decrease in $V_{\mathrm{OC}}$ with annealing is likely to be related to changes in the energy of the CT state at the polymer:fullerene with annealing that results in an increase in the interfacial disorder. ${ }^{23,44}$ Fig. 5d shows the overall power conversion efficiency of the DF-P3HT: PCBM solar cells as a function of MW. A record average efficiency of $3.8 \%$ is obtained for as-cast DF-P3HT:PCBM devices with $\mathrm{MW}$ of $44 \mathrm{kDa}$. We also achieved a similar device performance for the same devices annealed at $100{ }^{\circ} \mathrm{C}$ for $10 \mathrm{~min}$. The $37 \mathrm{kDa}$ and $88 \mathrm{kDa}$ DF-P3HT:PCBM devices both show an increase in the performance after thermal annealing to $150{ }^{\circ} \mathrm{C}$. On-the-other hand thermal annealing at $150{ }^{\circ} \mathrm{C}$ has a negative effect on the overall power conversion efficiency for the $44 \mathrm{kDa}$ and $70 \mathrm{kDa}$ devices. The reason for this discrepancy might be the decrease in microstructural order along the $\pi-\pi$ direction with annealing which will result in poor charge transport properties inside the blend. A lowest efficiency of ca. $2.5 \%$ is obtained for annealed $70 \mathrm{kDa}$ DF-P3HT:PCBM devices which is attributed to the low microstructural order (evidenced by the decrease in alkyl stacking coherence length with annealing) and increase in $W$ after thermal annealing. The solar cell performance parameters of rr-P3HT:PCBM devices are shown in the Table 4. For as-cast rr-P3HT:PCBM devices an efficiency of $2.2 \%$ is recorded. With thermal annealing on rr-P3HT devices, the efficiency increases reaching a maximum value of $3.2 \%$. When comparing rr-P3HT:PCBM and $44 \mathrm{kDa}$ DF-P3HT: PCBM devices, the improvement in RR ( $\mathrm{MW}$ is similar) has led to a significant increase the performance particularly with the as-cast and low temperature annealing condition.

The EQE spectra of the DF and low RR devices are shown in Fig. S11 (ESI $\dagger$ ). The integrated $J_{\mathrm{SC}}$ values from these spectra are 
very similar to those obtained from $J-V$ measurement under solar simulation. For as-cast devices the $44 \mathrm{kDa}$ P3HT batch has the maximum quantum efficiency with value crossing beyond $65 \%$. The $44 \mathrm{kDa}$ blend also has the prominent $607 \mathrm{~nm}$ shoulder which is attribute to the degree of interchain ordering inside the blend. ${ }^{45,46}$ On the other hand the lowest MW P3HT has less EQE values and lower $607 \mathrm{~nm}$ shoulder peak intensity suggesting high disorder blend films. The intermediate (70 kDa) and high (88 kDa) as-cast P3HT devices have similar EQE values around $60 \%$. Upon mild annealing $\left(100{ }^{\circ} \mathrm{C}\right)$ the EQE values for $37 \mathrm{kDa}$ and $88 \mathrm{kDa} \mathrm{P} 3 \mathrm{HT}$ blends has slightly increased, whereas $44 \mathrm{kDa}$ and $70 \mathrm{kDa}$ have similar values of as-cast devices. Upon annealing to $150{ }^{\circ} \mathrm{C}$ the $70 \mathrm{kDa}$ batch devices have less EQE values as compared to other two thermal annealing conditions. Other P3HT batches have similar EQE value as observed in $100{ }^{\circ} \mathrm{C}$ annealing condition, except in $44 \mathrm{kDa}$ batches where the intensity of $607 \mathrm{~nm}$ peak reduces significantly in $150{ }^{\circ} \mathrm{C}$ annealed devices. This shows that interchain disorder increases when the blend film is annealed at $150{ }^{\circ} \mathrm{C}$ in these blends.

Although there is some variation in the device performance with change in MW for the DF-P3HT samples, the variation is not systematic and is not significant especially when compared to previous studies of MW effects ${ }^{15,19,47}$ in batches of P3HT with lower (and uncontrolled) regioregularity. This study thus shows that when the P3HT polymer has a high RR the performance of the devices can be retained even when increasing the MW. Moreover, it was also found that a high degree of RR eliminated the necessity of thermal annealing to achieve good device performance. It was also found that for certain MW DF-P3HT:PCBM batches thermal annealing can result in a decrease in solar cell performance. This could be due to increase in the phase segregation in higher RR P3HTs, forming neat P3HT and PCBM domains after thermal annealing. ${ }^{48}$

To summarise, a range of different techniques have been used to probe the electrical, thermal, optical and microstructural properties of pristine and blend P3HT films upon changing the MW and processing thermal conditions with RR fixed at $100 \%$. When the RR of the polymer is fixed and MW is varied, then an increase in the MW from $37 \mathrm{kDa}$ to $88 \mathrm{kDa}$ leads to: (i) a decrease in the HOMO energy level, (ii) an increase in the crystal size (melting point) and degree of crystallinity, (iii) a decrease in the conjugation length of the polymer, (iv) an increase in the coherence length along the $\pi-\pi$ direction. The effects of annealing on the pristine films are not pronounced with regard to HOMO energy levels (data not shown), exciton bandwidth, and Raman modes, being very similar to the as-cast films. From the microstructural analysis, annealing leads to increased coherence lengths of the polymer along both the alkyl and $\pi-\pi$ stacking directions. Comparing batches of P3HT with similar MW but different RR, increased RR of the pristine P3HT is linked to: (i) a decrease in the HOMO energy level, (ii) an increase in the crystal size and degree of crystallinity, (iii) an increase in the conjugation length of the polymer, (iv) an increase in the coherence length of the polymer along $\pi-\pi$ direction.
In blends with PCBM, the optical and microstructural properties were found to be best for the $44 \mathrm{kDa}$ exhibiting the lowest values of $W$, highest intensity of the $\mathrm{C}-\mathrm{C}$ intra-ring stretch mode peak and highest $\pi-\pi$ stacking coherence lengths. The effect of thermal in DF-P3HT:PCBM samples was found to be much less compared to samples based on lower RR P3HT. When comparing the rr-P3HT:PCBM and 44 kDa DF-P3HT: PCBM that have similar MW, the differences are similar to what was observed for the pristine P3HT films, with the rr-P3HT:PCBM sample exhibiting: (i) a lower conjugation length, and (ii) more polymer disorder. The coherence length and $d$-spacing along the alkyl side chain stacking direction was found to be higher for the lower RR P3HT:PCBM blends. However along $\pi-\pi$ direction increased RR helps to increase the $\pi-\pi$ stacking coherence length which is arguably more important for charge transport. The surface chemical composition of $\mathrm{P} 3 \mathrm{HT}$ was found to decrease with increase in the RR of the polymer.

\section{Conclusion}

In this study the way in which the physical properties and microstructure of P3HT films (with fixed RR) is influenced by variations in MW and processing conditions has been investigated. It was found that RR and MW are very important in determining the properties of the thin films which can also be influenced by the film processing condition like thermal annealing. It was also shown that polymer regioregularity is a very sensitive parameter, with increases in RR promoting reduced molecular and microstructural disorder in the polymer system. When the polymer RR is fixed (at 100\%) then changes in the MW are not as sensitive as compared to changes in RR. From this study a record high efficiency of 3.8\% was achieved for as-cast P3HT:PCBM devices using $44 \mathrm{kDa}$ DF-P3HT. A relation between RR and MW was also achieved through this study: a MW of around $40 \mathrm{kDa}$ was found to be sufficient to achieve good device performance, and annealing treatment can even be omitted when RR is high. No significant drop off in PCE with increasing MW was observed for the DF batches with a PCE of $\sim 3.6 \%$ achieved for annealed $88 \mathrm{kDa}$ devices. Since a performance of more than $4 \%$ was achieved in as-cast P3HT:PCBM devices based on the $44 \mathrm{kDa}$ batch, DF-P3HT is a viable candidate for printing of devices over flexible substrate where thermal annealing treatment is not possible.

\section{Experimental}

\section{Materials}

rr-P3HT was purchased from Rieke Metals (4002-E) with $M_{\mathrm{w}}$ of $51 \mathrm{kDa}$ and dispersity of $D=2.4$. The DF-P3HT with different $M_{\mathrm{w}}$ are inhouse synthesised with procedure mentioned elsewhere. ${ }^{13}$ Other solvents and chemicals are purchased from SigmaAldrich and used as received unless mentioned otherwise.

\section{Material and film characterization}

P3HT with different MW are spin coated over quarts/PEIE substrate for UV-Vis absorption and Resonant Raman measurement. Absorption spectra were measured using a PerkinElmer Lembda 
950 spectrophotometer with an integrating sphere. Resonant Raman measurements were performed using a confocal microscope system (WITec, alpha $300 \mathrm{R})$ with a $100 \times$ objective $(\mathrm{NA}=0.9)$ under ambient conditions. A $532 \mathrm{~nm}$ laser was used to excite the samples which were placed on a piezo crystal-controlled scanning stage. The spectra are collected using 600 line $\mathrm{mm}^{-1}$ grating. To avoid sample damage, a low laser power $(\sim 50 \mu \mathrm{W})$ was applied during measurements.

GIWAXS measurement were conducted in the Australian Synchrotron SAXS/WAXS beamline. ${ }^{49}$ The P3HT films with different $M_{\mathrm{w}}$ were deposited over a Si/PEIE substrate with spin coating parameters similar to the ones employed for device fabrication. A $9 \mathrm{keV}$ X-ray photo energy was used and the $2 \mathrm{D}$ scattered patterns were recorded using a Pilatus $1 \mathrm{M}$ detector. The distance between the sample and the detector is calibrated using a silver behenate powder. The films were not exposed for more than a second at a single spot to avoid beam damage.

A detailed experimental procedure on the NEXAFS measurement can be found in our recently published paper. ${ }^{14}$

\section{Device fabrication and device characterization}

Organic solar cells with ITO/PEIE/(different P3HT:PCBM)/ $\mathrm{MoO}_{3} / \mathrm{Ag}$ inverted configuration was employed in this study. A detailed device fabrication procedure and basic characterisation procedure is mentioned in our previous study. ${ }^{23}$ Briefly, glass/ITO substrates were ultrasonicated with acetone and IPA solution consecutively followed by air-oxygen plasma treatment. A thin layer of polyethyleneamine (PEIE) was formed by spincoating from a $0.4 \mathrm{wt} \%$ 2-methoxyethanol solution and annealing at $100{ }^{\circ} \mathrm{C}$ for $10 \mathrm{~min}$. The P3HT:PCBM blend solution was prepared in 1,2 dichlorobenzene with a $1: 1$ weight ratio and total solution concentration of $40 \mathrm{mg} \mathrm{ml}^{-1}$. The blend solution was spin coated over the ITO/PEIE substrate inside a $\mathrm{N}_{2}$ filled glovebox at $1200 \mathrm{rpm}$ resulting in films thickness between 260$320 \mathrm{~nm}$ (measured using a Dektak 150 surface profilometer). A hole extraction layer $\mathrm{MoO}_{3}(13-15 \mathrm{~nm})$ and $\mathrm{Ag}$ metal electrode $(100 \mathrm{~nm})$ were thermally evaporated under vacuum at a base pressure of $7 \times 10^{-7} \mathrm{mbar}$. The devices were encapsulated inside the glovebox and taken out for characterization.

\section{Conflicts of interest}

There are no conflicts to declare.

\section{Acknowledgements}

We acknowledge A/Prof. Qiaoliang Bao and Mr Qingdong Ou, Materials Science and Engineering, Monash University for helping with the Resonant Raman measurement. The authors would also like to thank Dr Narendra Pai, Chemical Engineering, Monash University for helping in conducting DSC measurements. This word was partially supported by the Department of Science and Technology Australian-India Strategic Research Fund (grant number AISRF53765).

\section{References}

1 G. Yu, J. Gao, J. C. Hummelen, F. Wudl and A. J. Heeger, Polymer Photovoltiac Cells: Enhanced Efficiencies Via a Network of Internal Donor-Acceptor Heterojunctions, Science, 1995, 270(5243), 1789.

2 W. Zhao, S. Li, H. Yao, S. Zhang, Y. Zhang, B. Yang and J. Hou, Molecular Optimization Enables over 13\% Efficiency in Organic Solar Cells, J. Am. Chem. Soc., 2017, 139(21), 7148-7151.

3 S. Li, L. Ye, W. Zhao, H. Yan, B. Yang, D. Liu, W. Li, H. Ade and J. Hou, A Wide Band Gap Polymer with a Deep Highest Occupied Molecular Orbital Level Enables 14.2\% Efficiency in Polymer Solar Cells, J. Am. Chem. Soc., 2018, 140(23), 7159-7167.

4 A. Ng, X. Liu, W. Y. Jim, A. B. Djurišić, K. C. Lo, S. Y. Li and W. K. Chan, P3HT: PCBM Solar Cells-the Choice of Source Material, J. Appl. Polym. Sci., 2014, 131(2), 39776.

5 R. Po, A. Bernardi, A. Calabrese, C. Carbonera, G. Corso and A. Pellegrino, From Lab to Fab: How Must the Polymer Solar Cell Materials Design Change? - an Industrial Perspective, Energy Environ. Sci., 2014, 7(3), 925-943.

6 C. J. Mulligan, M. Wilson, G. Bryant, B. Vaughan, X. Zhou, W. J. Belcher and P. C. Dastoor, A Projection of CommercialScale Organic Photovoltaic Module Costs, Solar Energy Mater. Sol. Cells, 2014, 120(Part A), 9-17.

7 S. Ludwigs, P3HT Revisited-from Molecular Scale to Solar Cell Devices, Springer, 2015.

8 N. Espinosa, M. Hosel, M. Jorgensen and F. C. Krebs, Large Scale Deployment of Polymer Solar Cells on Land, on Sea and in the Air, Energy Environ. Sci., 2014, 7(3), 855-866.

9 F. Liu, J. Zhang, Z. Zhou, J. Zhang, Z. Wei and X. Zhu, Poly(3-Hexylthiophene)-Based Non-Fullerene Solar Cells Achieve High Photovoltaic Performance with Small Energy Loss, J. Mater. Chem. A, 2017, 5(32), 16573-16579.

10 J.-F. Chang, J. Clark, N. Zhao, H. Sirringhaus, D. W. Breiby, J. W. Andreasen, M. M. Nielsen, M. Giles, M. Heeney and I. McCulloch, Molecular-Weight Dependence of Interchain Polaron Delocalization and Exciton Bandwidth in HighMobility Conjugated Polymers, Phys. Rev. B: Condens. Matter Mater. Phys., 2006, 74(11), 115318.

11 X. M. Jiang, R. Österbacka, O. Korovyanko, C. P. An, B. Horovitz, R. A. J. Janssen and Z. V. Vardeny, Spectroscopic Studies of Photoexcitations in Regioregular and Regiorandom Polythiophene Films, Adv. Funct. Mater., 2002, 12(9), 587-597.

12 Y. Kim, S. Cook, S. M. Tuladhar, S. A. Choulis, J. Nelson, J. R. Durrant, D. D. C. Bradley, M. Giles, I. McCulloch, C.-S. Ha and M. Ree, A Strong Regioregularity Effect in SelfOrganizing Conjugated Polymer Films and High-Efficiency Polythiophene:Fullerene Solar Cells, Nat. Mater., 2006, 5(3), 197-203.

13 C. Naresh, C. Y. L. Amelia, K. Anil, R. M. Christopher and K. Dinesh, Effect of Regioregularity on Recombination Dynamics in Inverted Bulk Heterojunction Organic Solar Cells, J. Phys. D: Appl. Phys., 2018, 51(1), 015501. 
14 N. Chandrasekaran, C. Li, S. Singh, A. Kumar, C. R. McNeill, S. Huettner and D. Kabra, Role of Molecular and Interchain Ordering in the Formation of a $\delta$-Hole-Transporting Layer in Organic Solar Cells, ACS Appl. Mater. Interfaces, 2020, 12(3), 3806-3814.

15 R. Mauer, M. Kastler and F. Laquai, The Impact of Polymer Regioregularity on Charge Transport and Efficiency of P3ht:Pcbm Photovoltaic Devices, Adv. Funct. Mater., 2010, 20(13), 2085-2092.

16 S. Ebadian, B. Gholamkhass, S. Shambayati, S. Holdcroft and P. Servati, Effects of Annealing and Degradation on Regioregular Polythiophene-Based Bulk Heterojunction Organic Photovoltaic Devices, Solar Energy Mater. Sol. Cells, 2010, 94(12), 2258-2264.

17 C. Müller, E. Wang, L. M. Andersson, K. Tvingstedt, Y. Zhou, M. R. Andersson and O. Inganäs, Influence of Molecular Weight on the Performance of Organic Solar Cells Based on a Fluorene Derivative, Adv. Funct. Mater., 2010, 20(13), 2124-2131.

18 J. C. Bijleveld, A. P. Zoombelt, S. G. J. Mathijssen, M. M. Wienk, M. Turbiez, D. M. de Leeuw and R. A. J. Janssen, Poly(Diketopyrrolopyrrole-Terthiophene) for Ambipolar Logic and Photovoltaics, J. Am. Chem. Soc., 2009, 131(46), 16616-16617.

19 F. Liu, D. Chen, C. Wang, K. Luo, W. Gu, A. L. Briseno, J. W. P. Hsu and T. P. Russell, Molecular Weight Dependence of the Morphology in P3HT:PCBM Solar Cells, ACS Appl. Mater. Interfaces, 2014, 6(22), 19876-19887.

20 D. Spoltore, T. Vangerven, P. Verstappen, F. Piersimoni, S. Bertho, K. Vandewal, N. Van den Brande, M. Defour, B. Van Mele, A. De Sio, J. Parisi, L. Lutsen, D. Vanderzande, W. Maes and J. V. Manca, Effect of Molecular Weight on Morphology and Photovoltaic Properties in P3HT:PCBM Solar Cells, Org. Electron., 2015, 21(Supplement C), 160-170.

21 M. Morana, P. Koers, C. Waldauf, M. Koppe, D. Muehlbacher, P. Denk, M. Scharber, D. Waller and C. Brabec, Organic Field-Effect Devices as Tool to Characterize the Bipolar Transport in Polymer-Fullerene Blends: The Case of P3HT-PCBM, Adv. Funct. Mater., 2007, 17(16), 3274-3283.

22 C. R. McNeill, J. J. M. Halls, R. Wilson, G. L. Whiting, S. Berkebile, M. G. Ramsey, R. H. Friend and N. C. Greenham, Efficient Polythiophene/Polyfluorene Copolymer Bulk Heterojunction Photovoltaic Devices: Device Physics and Annealing Effects, Adv. Funct. Mater., 2008, 18(16), 2309-2321.

23 N. Chandrasekaran, E. Gann, N. Jain, A. Kumar, S. Gopinathan, A. Sadhanala, R. H. Friend, A. Kumar, C. R. McNeill and D. Kabra, Correlation between Photovoltaic Performance and Interchain Ordering Induced Delocalization of Electronics States in Conjugated Polymer Blends, ACS Appl. Mater. Interfaces, 2016, 8(31), 20243-20250.

24 P. Kohn, S. Huettner, H. Komber, V. Senkovskyy, R. Tkachov, A. Kiriy, R. H. Friend, U. Steiner, W. T. S. Huck, J.-U. Sommer and M. Sommer, On the Role of Single Regiodefects and Polydispersity in Regioregular
Poly(3-Hexylthiophene): Defect Distribution, Synthesis of Defect-Free Chains, and a Simple Model for the Determination of Crystallinity, J. Am. Chem. Soc., 2012, 134(10), 4790-4805.

25 W. Huang, N. Chandrasekaran, S. K. K. Prasad, E. Gann, L. Thomsen, D. Kabra, J. M. Hodgkiss, Y.-B. Cheng and C. R. McNeill, Impact of Fullerene Mixing Behavior on the Microstructure, Photophysics, and Device Performance of Polymer/Fullerene Solar Cells, ACS Appl. Mater. Interfaces, 2016, 8(43), 29608-29618.

26 W. Huang, E. Gann, N. Chandrasekaran, L. Thomsen, S. K. K. Prasad, J. M. Hodgkiss, D. Kabra, Y.-B. Cheng and C. R. McNeill, Isolating and Quantifying the Impact of Domain Purity on the Performance of Bulk Heterojunction Solar Cells, Energy Environ. Sci., 2017, 10(8), 1843-1853.

27 B. A. Collins, E. Gann, L. Guignard, X. He, C. R. McNeill and H. Ade, Molecular Miscibility of Polymer-Fullerene Blends, J. Phys. Chem. Lett., 2010, 1(21), 3160-3166.

28 W. Huang, E. Gann, Y.-B. Cheng and C. R. McNeill, In-Depth Understanding of the Morphology-Performance Relationship in Polymer Solar Cells, ACS Appl. Mater. Interfaces, 2015, 7(25), 14026-14034.

29 M. T. Dang, L. Hirsch, G. Wantz and J. D. Wuest, Controlling the Morphology and Performance of Bulk Heterojunctions in Solar Cells. Lessons Learned from the Benchmark Poly(3-Hexylthiophene):[6,6]-Phenyl-C 61 -Butyric Acid Methyl Ester System, Chem. Rev., 2013, 113(5), 3734-3765.

30 H. Bässler and A. Köhler, Charge Transport in Organic Semiconductors, in Unimolecular and Supramolecular Electronics I, Springer, 2011, pp. 1-65.

31 M. Onoda, K. Tada and H. Nakayama, Electronic Energy States of Organic Interfaces Studied by Low-Energy Ultraviolet Photoemission Spectroscopy, J. Appl. Phys., 1999, 86(4), 2110-2115.

32 J. Clark, C. Silva, R. H. Friend and F. C. Spano, Role of Intermolecular Coupling in the Photophysics of Disordered Organic Semiconductors: Aggregate Emission in Regioregular Polythiophene, Phys. Rev. Lett., 2007, 98(20), 206406.

33 P. J. Brown, D. S. Thomas, A. Köhler, J. S. Wilson, J.-S. Kim, C. M. Ramsdale, H. Sirringhaus and R. H. Friend, Effect of Interchain Interactions on the Absorption and Emission of Poly(3-Hexylthiophene), Phys. Rev. B: Condens. Matter Mater. Phys., 2003, 67(6), 064203.

34 F. C. Spano, Modeling Disorder in Polymer Aggregates: The Optical Spectroscopy of Regioregular Poly(3-Hexylthiophene) Thin Films, J. Chem. Phys., 2005, $122(23), 234701$.

35 G. Louarn, M. Trznadel, J. P. Buisson, J. Laska, A. Pron, M. Lapkowski and S. Lefrant, Raman Spectroscopic Studies of Regioregular Poly(3-Alkylthiophenes), J. Phys. Chem., 1996, 100(30), 12532-12539.

36 J.-J. Yun, J. Peet, N.-S. Cho, G. C. Bazan, S. J. Lee and M. Moskovits, Insight into the Raman Shifts and Optical Absorption Changes Upon Annealing Polymer/Fullerene Solar Cells, Appl. Phys. Lett., 2008, 92(25), 251912.

37 T. Wang, A. J. Pearson, D. G. Lidzey and R. A. L. Jones, Evolution of Structure, Optoelectronic Properties, and 
Device Performance of Polythiophene:Fullerene Solar Cells During Thermal Annealing, Adv. Funct. Mater., 2011, 21(8), 1383-1390.

38 Y. Gao and J. K. Grey, Resonance Chemical Imaging of Polythiophene/Fullerene Photovoltaic Thin Films: Mapping Morphology-Dependent Aggregated and Unaggregated C. . C Species, J. Am. Chem. Soc., 2009, 131(28), 9654-9662.

39 W. Sebastian, J. Razzell, H. Ji-Seon and K. Raman, Spectroscopy as an Advanced Structural Nanoprobe for Conjugated Molecular Semiconductors, J. Phys. D: Appl. Phys., 2017, 50(7), 073001.

40 Y. Yacoby and E. Ehrenfreund, Resonant Raman Scattering in Conjugated Polymers, in Light Scattering in Solids Vi: Recent Results, Including High-Tc Superconductivity, ed. M. Cardona and G. Güntherodt, Springer Berlin Heidelberg, Berlin, Heidelberg, 1991, pp. 73-135.

41 W. C. Tsoi, D. T. James, J. S. Kim, P. G. Nicholson, C. E. Murphy, D. D. Bradley, J. Nelson and J.-S. Kim, The Nature of in-Plane Skeleton Raman Modes of P3ht and Their Correlation to the Degree of Molecular Order in P3HT: PCBM Blend Thin Films, J. Am. Chem. Soc., 2011, 133(25), 9834-9843.

42 M. M. Nahid, E. Gann, L. Thomsen and C. R. McNeill, NEXAFS Spectroscopy of Conjugated Polymers, Eur. Polym. J., 2016, 81, 532-554.

43 Y. Vaynzof, D. Kabra, L. Zhao, L. L. Chua, U. Steiner and R. H. Friend, Surface-Directed Spinodal Decomposition in
Poly[3-Hexylthiophene] and $\mathrm{C}_{61}$-Butyric Acid Methyl Ester Blends, ACS Nano, 2011, 5(1), 329-336.

44 N. Jain, N. Chandrasekaran, A. Sadhanala, R. H. Friend, C. R. McNeill and D. Kabra, Interfacial Disorder in Efficient Polymer Solar Cells: The Impact of Donor Molecular Structure and Solvent Additives, J. Mater. Chem. A, 2017, 5(47), 24749-24757.

45 L. Li, G. Lu and X. Yang, Improving Performance of Polymer Photovoltaic Devices Using an Annealing-Free Approach Via Construction of Ordered Aggregates in Solution, J. Mater. Chem., 2008, 18(17), 1984-1990.

46 M. C. Gurau, D. M. Delongchamp, B. M. Vogel, E. K. Lin, D. A. Fischer, S. Sambasivan and L. J. Richter, Measuring Molecular Order in Poly(3-Alkylthiophene) Thin Films with Polarizing Spectroscopies, Langmuir, 2007, 23(2), 834-842.

47 P. Schilinsky, U. Asawapirom, U. Scherf, M. Biele and C. J. Brabec, Influence of the Molecular Weight of Poly(3-Hexylthiophene) on the Performance of Bulk Heterojunction Solar Cells, Chem. Mater., 2005, 17(8), 2175-2180.

48 C. H. Woo, B. C. Thompson, B. J. Kim, M. F. Toney and J. M. J. Fréchet, The Influence of Poly(3-Hexylthiophene) Regioregularity on Fullerene-Composite Solar Cell Performance, J. Am. Chem. Soc., 2008, 130(48), 16324-16329.

49 N. M. Kirby, S. T. Mudie, A. M. Hawley, D. J. Cookson, H. D. T. Mertens, N. Cowieson and V. Samardzic-Boban, A LowBackground-Intensity Focusing Small-Angle X-Ray Scattering Undulator Beamline, J. Appl. Crystallogr., 2013, 46(6), 1670-1680. 